\title{
AMAZÔNIA: \\ sociedade, fronteiras e políticas
}

\author{
INTRODUÇÃO
}

\author{
Edna Castro*
}

Este dossiê - Amazônia: sociedade, fronteiras e políticas - apresenta, no conjunto formado por seis artigos, uma análise crítica dos processos de dominação e dos efeitos nas estruturas locais das políticas desenvolvimentistas. Reúne leituras baseadas em caminhos analíticos, enfoques metodológicos e corpus disciplinar diversos, explorando a revisão conceitual a partir de experiências de campo, da pesquisa etnográfica aos estudos mais gerais. São textos que dialogam entre si no desafio de entender processos e contribuir para novas pesquisas sobre a Amazônia.

O dossiê visa a evidenciar os conflitos e os processos de dominação existentes, que permanecem sob velhas e novas formas. O objetivo foi organizar textos e argumentos construídos por tradições teóricas diversas sobre os processos de dominação, as estratégias do Estado materializa-

* Doutora em Sociologia. Professora da Universidade Federal do Pará (UFPA). Coordenadora do Grupo de Pesquisa Trabalho, Empresas e Transformações Sociais, do Diretório do CNPq.

Campus da UFPA. Av. Augusto Correa, n.01. Guamá. Cep: 66075-090. Belém - Pará - Brasil. edna.mrcastro@gmail.com das em suas políticas e a ação do mercado. Buscase fazer uma leitura da Amazônia brasileira contemporânea e de sua fronteira com países amazônicos. Na perspectiva assumida neste dossiê, a Amazônia precisa ser lida a contrapelo dos discursos opacos que querem ver a região como verde ou ligada a potencialidades econômicas que precisam, a todo custo, chegar aos mercados. O dossiê parte da análise da formação histórica da Amazônia, das identidades em trânsito e das nacionalidades, do protagonismo de grupos em contextos políticos distintos e da dinâmica econômica nacional e internacional. Examina o Estado, suas políticas e os interesses de mercado que têm presidido a formulação de planos e programas desenvolvimentistas direcionados às novas fronteiras de recursos, que extrapolam os limites políticos dos territórios nacionais. Incorpora, assim, a dimensão transnacional dos projetos de infraestrutura e de logística de transporte, que representam a atual investida na modernização da Pan-Amazônia.

Os autores procuraram revelar a complexidade dos novos processos de dominação social 
relacionados com as políticas de desenvolvimento e os grandes empreendimentos nacionais e internacionais. Examinam ainda a profusão de discursos que associam sustentabilidade e Amazônia, produzidos em universos conceituais diversos, que alicerçam um processo de modernização que desconsidera a organização de grupos sociais, a presença de etnias e de saberes tradicionais ancorados em outras visões de mundo. A questão central permanece a disputa pela apropriação de territórios e de recursos naturais. Por isso, como mostra Almeida neste dossiê, estão em curso, no âmbito do Estado, novas formas de desregulamentação e de deslegitimação de direitos e sistemas de uso de territórios de população tradicional. De outro lado, como registra o artigo de Baines, da relação entre Estado e sociedade emergem contradições sociais e políticas que têm produzido ações coletivas, sob a forma de mobilizações que extrapolam as fronteiras brasileiras. E que resistem à construção de grandes obras de infraestrutura, a projetos de investimento nos setores de mineração, energia (hidrelétricas), agronegócio, e às obras de infraestrutura de transporte - rodoviário, ferroviário, fluvial e portuário -, o que é demonstrado no texto de Castro, no contexto de uma economia globalizada, com fortes ações do mercado internacional. Ressalta essa autora os dispositivos do modelo de produção de commodities para o mercado exportador e, mais recentemente, o novo mundo de mercadorias que se forma em torno dos bens e serviços ambientais.

A crise econômica mundial recente, que provocou uma retração do mercado mundial e uma redução na dinâmica das trocas, mostrou, no entanto, que os produtos primários continuam a ter papel importante na economia e na balança comercial brasileira. Trata-se de produtos agrícolas e de bens primários, baseados nos recursos naturais. Se o Brasil diversificou, ao longo das últimas décadas, seu parque industrial e aumentou sua inserção industrial na economia mundo, não deixa de ser um produtor e exportador de commodities e aposta, de forma determinante, no crescimento do agrobusiness, do mercado exportador de alimentos. Com a globalização e o aumento de competitividade no mercado, observa-se, no âmbito local, a exemplo do que ocorre hoje em diferentes estados e áreas da Amazônia brasileira, que as empresas nacionais e internacionais reforçam suas estratégias de apropriação de terras e de recursos, para investimentos imediatos ou futuros, com reserva de nichos de mercado. Esse processo tende a aprofundar-se, se considerarmos a dinâmica atual de mercado, a globalização das economias e a corrida pelo crescimento econômico, para sair das crises do capitalismo ou para assegurar o processo de acumulação e de domínio político em agendas globais.

Novos conceitos e paradigmas de interpretação da história da Amazônia são importantes para visibilizar processos e práticas sociais obscurecidas por enfoques teóricos reducionistas presentes em boa parte da produção acadêmica sobre essa região. Este dossiê traz elementos que contribuem para a compreensão de dimensões e processos pouco abordados. Os artigos retomam a análise de estrutura e ação, empreendendo um esforço teórico e metodológico para ultrapassar a visão dicotômica e procurar articular objetividade e subjetividade, ao abordar a ação de sujeitos sociais e as políticas públicas, refletindo sobre velhas e novas noções que buscam compreender processos, conflitos e ações coletivas.

As políticas governamentais têm sido analisadas em diferentes contextos, mostrando-se que as mobilizações coletivas se expressam sobre dado território, em nome de direitos territoriais e identidades. Aprofunda-se o processo de concessão dos bens públicos à apropriação privada por meio de procedimentos que têm levado à flexibilização de regras e dispositivos políticos, contrariando a promoção da cidadania e a equidade em relação aos bens e serviços ambientais. Ações coletivas e formas novas de organização política emergem nesse cenário, marcado por interesses contraditórios e divergentes.

João Pacheco de Oliveira, ao retomar es- 
tudos clássicos da antropologia, procura mostrar que certas análises desmerecem a história e, por isso, acabam minimizando o entendimento do "horizonte político dos indígenas". Seu texto tem como fio condutor a noção de situação histórica, que entende ser a "capacidade de determinados agentes (instituições e organizações) de produzirem certa ordem política por meio da imposição de interesses, valores e padrões organizativos aos outros componentes da cena política”. Ao discutir essa noção, procura distingui-la de outros conceitos da antropologia política, interrogando os processos de dominação na Amazônia e identificando formas do exercício da dominação e interesses e valores gerais a elas vinculados.

Ao ressaltar a relevância da investigação histórica nos estudos etnológicos, João Pacheco de Oliveira recupera noções das ciências sociais marcadas pela reflexão política, como as encontradas em Marx e Gramsci, defendendo um enfoque rigoroso para entender a dinâmica e a variabilidade de posições dos povos indígenas. Toma como referência os Ticuna e sua capacidade de construir identidades e especificidades na relação com a sociedade, processando continuamente, em função da situação histórica, mediações para além da experiência identitária. A perspectiva metodológica considera escalas diversas da interação, em tempos e espaços específicos que conformam dinâmicas particulares. A reflexão do autor leva em conta a percepção de que os Ticunas sempre se defrontaram com situações históricas distintas e com elas interagiram a partir de sua organização social e tomaram posição quanto aos eventuais efeitos sobre eles dos projetos da sociedade nacional.

Baseado nesse quadro teórico, Pacheco de Oliveira interpreta as dinâmicas sociais e políticas em grandes períodos da ocupação colonial na Amazônia, mostrando as tensões, as disputas e, sobretudo, as formas de dominação impostas pela sociedade colonial para garantir a subordinação dos povos indígenas, do século XVI até as primeiras décadas do século XX. Com base no universo de análise - a realidade histórica dos Ticuna -, observa a ocupação no vale do rio Amazonas, trazendo ao leitor uma interpretação das estruturas mais gerais da dominação colonial. Não limita, portanto, sua análise à escala local, ao contrário, pois, como esclarece, "é possível que as diferentes situações da história Ticuna aqui estudadas se assemelhem bastante a outras por que passaram populações indígenas diferentes e localizadas em pontos distintos da Amazônia”. Considera, assim, uma questão empírica verificar se a "história de outras populações indígenas na Amazônia podem ou não aceitar um recorte", conforme proposto. Ao incorporar a dimensão histórica aos estudos etnográficas, Pacheco de Oliveira torna sua reflexão singular no sentido de que contribui para a formulação de questões teóricas e ultrapassa o alcance da análise de grupos localizados, propondo uma interpretação mais inclusiva da sociedade nacional. Elege a noção de situação histórica como ferramenta capaz de revelar relações sociais numa perspectiva multiescalar.

Duas observações são necessárias para precisar a noção de situação histórica: de um lado, trata-se do modelo que se pauta por uma construção do observador com intuitos analíticos para poder apreender a capacidade ordenadora efetiva presente nos grupos e em seus processos sociais concretos; de outro, corresponde à possibilidade de realizar estudos comparativos que transcendam a reprodução de relações sociais e revelem mudanças. Assim, Pacheco de Oliveira reafirma a noção de sujeito da ação, de mobilização política e, portanto, a possibilidade de invenção contínua de processos identitários em um novo cenário político.

$\mathrm{O}$ artigo de Stephan Baines - O movimento político indígena em Roraima: identidades indígenas e nacionais na fronteira Brasil-Guiana , por outro ângulo, também discute identidades, mas ressalta a situação de fronteira transnacional e os problemas interpretativos provocados pela relação entre identidade e nacionalidade de grupos que vivem em situação de trânsito permanente entre 
países, com forte presença de grupos étnicos. Retoma as reflexões teóricas sobre a construção e a superposição de identidades no contexto transnacional com base nos estudos de Roberto Cardoso de Oliveira sobre nacionalidade e etnicidade, notadamente sobre etnias localizadas entre estados nacionais, enfocando os Makuxi e os Wapichana na fronteira Brasil-Guiana, no extremo norte da Amazônia brasileira.

$\mathrm{O}$ autor analisa o movimento político indígena - que, segundo ele, firmou-se com protagonismo no Estado de Roraima a partir da década de 70 do século XX - e examina a interface das identidades indígenas com as identidades nacionais de brasileiro e guianense, como convivem e quais os trânsitos identitários, propondo a noção de identidades contextualizadas.

Assim como Oliveira, o artigo de Baines recorre à história para mostrar modelos de submissão e dominação impostos aos indígenas. Examina as tensões relativas às formas de ocupação estratégico-militar das fronteiras políticas do Brasil com a Guiana e a Venezuela, citando a superexploração do trabalho dos grupos indígenas e elaborando uma etnografia histórica da dominação.

Baines evidencia ainda a produção de discursos reducionistas que pretendem classificar os índios e, ao mesmo tempo, invisibilizá-los fora das categorias impostas, procurando transformálos, por exemplo, em índios vestidos ou em camponeses. O protagonismo de grupos, sobretudo como é observado no processo de demarcação contínua da Terra Indígena (TI) Serra Raposa do Sol, em Roraima, corresponde à produção de um contradiscurso sobre a etnicidade e a territorialidade, situações políticas historicamente contextualizadas. O autor mostra como esses povos fortaleceram suas identidades, apesar da subordinação por "séculos de contato interétnico com segmentos das sociedades nacionais brasileira e guianense, e décadas de subordinação a fazendeiros e garimpeiros que invadiam suas terras", com larga trajetória de exploração de sua força de trabalho.
O texto de Baines traz uma contribuição importante para o debate sobre identidades e nacionalidades e sobre a interface de identidades diferentes, múltiplas, nacionais e étnicas. De certa forma, ajuda a elucidar e a compreender situações diferentes que conformam o universo de etnias que vivem em dupla inserção nacional, com seus territórios originais marcados por acordos políticos binacionais de delimitação de fronteiras e dispositivos reguladores pertinentes a cada realidade nacional. E pode iluminar a revisão teórica de noções que têm servido para descrever situações similares, mas com certa formalidade conceitual que deixa escapar dinâmicas mais recentes nos processos identitários nas fronteiras brasileiras, como é o caso da larga faixa da fronteira amazônica brasileira.

Baines abstrai, de suas análises, o conceito de "identidades contextualizadas", o que permite pensar no espaço da ação política e de pertencimento a grupos, sem deixar de entender e agir em um universo de relações sociais e políticas que se dão em espaços institucionais e em escalas diferentes, em que se incluem regulações de nacionalidades diferentes. $\mathrm{O}$ autor procura, assim, mostrar como se sobrepõem as identidades em áreas de fronteira política e suas interfaces como identidades contextualizadas.

O texto de Edna Castro apresenta um panorama geral de modelos de desenvolvimento nos quais o Estado tem tido um papel relevante, e a trajetória de políticas de expansão e de ordenamento no Brasil. O Estado brasileiro, hoje, adota um planejamento que se fundamenta em uma "visão estratégica" na qual a Amazônia é considerada região central na produção de commodities e na integração ao mercado mundial, conforme mostram os projetos e ações governamentais, de médio e curto prazo, para a infraestrutura de transporte, energia e comunicação. O planejamento segue as linhas de demarcação de maneira semelhante ao que ocorreu com a cessão de terras e a liberação da instalação para o Programa Grande Carajás, nos anos 70, no período do Governo Militar. As transfor- 
mações em curso mostram a rapidez do processo de apropriação de terras e de assentamento das bases de um projeto empresarial por parte de grandes empresas. Elas só podem ser explicadas recorrendo-se à analise do processo de acumulação de capital, com o avanço em novas fronteiras e o deslocamento, no território, dos interesses pelo uso da terra. Trata-se de um avanço em direção às fronteiras políticas mais preservadas da Amazônia continental. Nesse novo contexto do século XXI, Edna Castro discute a relação entre território, territorialidade e os conflitos, criticando a reedição das velhas práticas de planejamento baseadas na integração nacional, em que a logística de transporte tem um papel fundamental.

A alteração territorial que presenciamos hoje, na Amazônia, resulta efetivamente de importantes mudanças que ocorreram na sociedade e na economia nas últimas décadas. Dentre essas mudanças, destacam-se as novas demandas do mercado mundial e a diferenciação interna de setores econômicos que alteraram os processos de produção, os sistemas de uso da terra e a estrutura da propriedade. Seu entendimento requer que se considere a interação entre os processos locais e a dinâmica de mercados globais, fundamental para se identificarem as conexões lógicas que explicam o complexo mercado transnacional e a pressão de estruturas e de agentes econômicos sobre os recursos naturais. O texto de Edna Castro interpreta os efeitos locais do movimento da economia de alguns setores-chave, como as cadeias produtivas da pecuária, da madeira e da agricultura intensiva, que estão ligados ao mercado global.

Procura observar a autora as políticas e o planejamento de longo prazo, que não somente reeditam os anos 70 e 80 do século passado, por meio de um regime de força e de um planejamento autoritário, mas também incorporam noções como ordenamento e controle, numa perspectiva gerencialista, subordinando às agendas mercantis a ação política e as estratégias de redução da desigualdade, de respeito às identidades, às etnias e aos modos de vida, o que é assegurado pelo texto constitucional. O que está em jogo, portanto, é a garantia do direito de cidadania e do exercício desse direito pelos sujeitos políticos.

Alfredo Wagner de Almeida traz relevante contribuição para a discussão sobre as políticas, os discursos e a lógica burocrática do Estado brasileiro. Argumenta que a concepção das políticas governamentais e das estratégias do Estado delas decorrentes tem continuamente minimizado, na Amazônia, a ordem e a organização social existente nos territórios de grupos tradicionais, de várias conformações sociais e étnicas. O autor chama a atenção para a rapidez dos processos, o tempo célere dos grandes projetos de investimento, o que revela a articulação entre o mercado e a reestruturação das ações do Estado. Mostra que está em curso uma rápida flexibilização das normas jurídicas que asseguram os direitos territoriais de povos e comunidades tradicionais e os dispositivos que regulam o uso de unidades de conservação de terras, de quilombolas e indígenas, por exemplo. As ações do Estado têm objetivado atender aos interesses do mercado e à demanda de um crescimento econômico baseado principalmente em commodities minerais e agrícolas. Wagner de Almeida discute, portanto, os processos que têm reconfigurado a noção de território e as consequências para aqueles que vivem na Amazônia, com estruturas sociais que se fundam em sistemas de uso comum da terra e dos recursos naturais.

Entende Almeida que são os processos de flexibilização, o mercado de terras e a apropriação dos recursos naturais que estão em jogo nas ações e estratégias do Estado. Descreve o autor os novos processos de dominação em curso, que incidem diretamente sobre os territórios de povos e comunidades tradicionais, "premidos entre a inocuidade das políticas de 'proteção' [...] e a ofensiva sobre seus recursos básicos desencadeada pelas medidas 'protecionistas"'. Almeida enfatiza que o território dos "outros" é diferente do território "das políticas", aquele com história e cultura enraizadas, o que permite falar de uma outra 
Amazônia, uma outra realidade não vista pelos dispositivos burocráticos. Para o autor, a lógica burocrática continua reproduzindo os erros na relação com os povos e as comunidades que habitam na região, como é verificado com os projetos do Programa Polamazônia, do Programa Polonoroeste e do Programa Grande Carajás, não por desconhecimento dos efeitos de grandes investimentos sobre a ordem social existente nesses lugares, mas pelo interesse no mercado de terras, e, por isso, na implementação de políticas de reorganização de espaços e territórios.

Nessa perspectiva, Almeida relaciona as instâncias de intervenção construídas como argumento para a rápida desregulamentação que atinge povos tradicionais na Amazônia e descreve os processos em curso e as alterações no âmbito das instituições: privatização das terras públicas; redução das áreas protegidas; tentativas de incorporação de novas extensões aos circuitos mercantis com base em interesses dos "ruralistas" e das mineradoras (reforma do Código Florestal, redução da faixa de fronteira, reforma do Código da Mineração); e flexibilização dos direitos territoriais. Finalmente, expõe o que considera como novas estratégias de expansão da fronteira que propiciam condições de ampliação da produção de commodities, forçando procedimentos que minimizam os direitos territoriais de povos e comunidades tradicionais, redefinindo os direitos dos "trabalhadores migrantes" e produzindo estigmatizações. Para o autor, os sentidos práticos de território transcendem o significado estrito das políticas fundiárias, ambientais ou minerais.

Com o objetivo de analisar os principais dispositivos de governança da exploração florestal na Amazônia brasileira, Marcelo Sampaio Carneiro faz uma leitura orientada pelas formulações teóricas da nova sociologia econômica e discute, em seu artigo, três dispositivos de regulação da indústria florestal na Amazônia: a certificação florestal, o modelo das florestas familiares e a política de concessões florestais. Esses instrumentos de governança, que tentam viabilizar a troca mercantil, estão relacionados com a problemática de uso dos recursos florestais e têm origem em políticas do Estado e nos interesses da economia florestal. Os debates que antecedam a formulação desses dispositivos foram marcados por concepções divergentes, tensões e conflitos. São dispositivos que visam a assegurar a legitimidade da troca. Em sua análise, o autor adota uma tipologia das formas de coordenação das atividades econômicas, procurando identificar as diferentes formas de governança da atividade florestal na Amazônia brasileira.

Para Carneiro, importa destacar os mecanismos de governança da gestão dos recursos florestais como possibilidade de enfrentar certa crise dos instrumentos tradicionais do Estado e garantir o cumprimento das políticas públicas que orientam a exploração dos recursos florestais. As alterações no Código Florestal, ora em debate no Congresso Nacional, traduzem interesses institucionais e jogos de poder em torno da floresta. Por isso, é importante compreender a dinâmica político-econômica subjacente à relação entre preservação da floresta tropical da Amazônia e crescimento econômico do setor madeireiro. Entende o autor que se trata de uma crítica à incapacidade do Estado para fazer valer sua autoridade sobre a sociedade, ou para responder às diferentes demandas que surgem de forma cada vez mais rápida, por pressões do mercado global.

Analisando as diferentes propostas de governança da atividade florestal na Amazônia, Carneiro entende que a certificação florestal na Amazônia brasileira "é uma tentativa de resolver o problema da exploração florestal predatória por meio da incitação de empresas a adotarem práticas sustentáveis de manejo florestal", o que tem implicado o aumento do preço devido à certificação - concessão do selo florestal que corresponde a uma convenção de qualidade - e ao acesso privilegiado a mercados consumidores mais exigentes.

O debate sobre os acordos entre empresas e agricultores familiares e as propostas de 
uso de florestas familiares acabou resultando em vários modelos, entre os quais o Safra Legal, o Florestas Familiares e o Manejo Florestal e Prestação de Serviços. Quanto à Lei de Gestão das Florestas Públicas, o dispositivo das concessões florestais teve como objetivo final atender às prerrogativas do setor madeireiro para supri-lo de matéria-prima, dando acesso seguro e permanente aos recursos naturais. A governança, na ótica das concessões florestais, é um dispositivo cujo principal ator é o Estado, que visa a promover o desenvolvimento da economia florestal na região. As análises de Carneiro chegam à conclusão de que a tendência da política de concessões é tornar-se a forma dominante de funcionamento da exploração florestal na Amazônia.

Philip Fearnside e William Laurance, no artigo Infraestrutura na Amazônia: as lições dos planos plurianuais, demonstram, com base em dados sistematizados sobre as ações dos Planos de Aceleração da Economia (PAC I e II), a fragilidade do sistema de avaliação ambiental em relação aos programas desenvolvimentistas e às obras que estão celeremente sendo implantadas na Amazônia.

Ao examinarem os planos plurianuais, desde o Brasil em Ação (1996-1999) até o atual PAC-2 (2012-2015), Fearnsidee Laurance deixam clara a necessidade de rever a maneira como são decididos e implantados os grandes programas de desenvolvimento e apontam, de referência aos PAC I e PAC II, "a necessidade de reconsiderar a prudência de vários projetos que os compõem”. Os Planos Plurianuais, por representarem grandes investimentos alocados pelo governo federal brasileiro para períodos de quatro anos, geram fortes impactos sobre o meio ambiente. Por isso, as obras, para serem iniciadas, têm de estar livres de constrangimentos legais. Daí a minimização da eficácia das instituições de defesa ambiental, como foi verificado no processo de licenciamento ambiental da Hidrelétrica de Belo Monte, que foi amplamento divulgado na sociedade nacional e internacional e apontou as lacunas e imprecisões dos estudos dos impactos sociais e ambientais.

Fearnside e Laurance enfatizam que as exigências de estudos de impactos ambientais não garantem, como instrumentos legais, que os projetos com avaliação negativa, social e ambientalmente, não sejam construídos. Os resultados contrariam a formulação do plano Avança Brasil, em 2001, segundo o qual a "pavimentação de estradas e outros projetos causariam impactos mínimos, devido às exigências atuais no Brasil de avaliações de impactos ambientais, à capacidade do País para monitorar por satélite o desmatamento, e a lei de crimes ambientais" (Lei federal n. ${ }^{\circ}$ 9.605, de 12 de fevereiro de 1998). Concluem Fearnside e Laurance que o desafio apresentado pelos planos plurianuais deixa clara a necessidade de fortalecer o sistema de avaliação de impacto ambiental, que não é sequer capaz de prever todos os tipos de impactos esperados pelos projetos dos planos, identificando mecanismos presentes que, contrariamente aos discursos oficiais, acabam levando ao aumento do desmatamento ou a outros processos reconhecidamente de violência ambiental. O planejamento burocrático, os tempos definidos pelos cronogramas das obras e pelos interesses da área de engenharia e a falta de transparência do processo de licenciamento são avaliados em estudos financiados, em geral, pelos próprios proponentes dos projetos, como é observado amplamente na Amazônia, colocando em jogo os direitos que envolvem a relação entre sociedade e natureza.

Espera-se que os textos que compõem este dossiê permitam reflexões para além deles mesmos. Procurou-se evidenciar práticas sociais e processos em uma perspectiva de pesquisa que priorizasse o entendimento da complexidade, para ultrapassar leituras reducionistas, marcadas pela categorização, pela invisibilidade ou pela estigmatização de grupos sociais que vivem na Amazônia, ou ainda noções dualistas e gerencialistas que impregnam, na atualidade, grande parte dos discursos e textos que falam da Amazônia e que têm exaustivamente priorizado o modelo desenvolvimentista. 
O dossiê buscou contribuir para o debate por meio da análise das dimensões da sociedade, dos processos de dominação, do aparecimento de novas fronteiras do capital, das políticas públicas e das estratégias de desregulamentação e de constrangimentos sociais e ambientais formuladas pela lógica burocrática. Examinam-se situações históricas, sujeitos sociais, conflitos, identidades e práticas sociais, em sua relação com formas de dominação específicas, em várias es- calas, e, sobretudo, sua articulação com as políticas desenvolvimentistas implementadas no país e nas suas fronteiras políticas que ocupam larga faixa da Pan-Amazônia. Espera-se que este dossiê possa sucitar uma visão crítica da Amazônia e instigue novas leituras sobre a produção da vida social, que tem muito a ver com as formas de identidade e de territorialidade.

(Recebido para publicação em 26 de março de 2012 ) (Aceito em 20 de abril de 2012 )

Edna Castro - Socióloga do Núcleo de Altos Estudos Amazônicos, da Universidade Federal do Pará - UFPA. Doutora em Sociologia pela École des Hautes Études en Sciences Sociales. Pós-doutora pelo Centre National de la Recherche Scientifique. Professora da UFPA. Pesquisadora do CNPq. Professora Visitante da Université de Québec à Montreal Departamento de Sociologia, Canadá; da Universidade de Brasília, UnB, Departamento de Sociologia e da Université Le Havre, França. Diretora do Núcleo de Altos Estudos Amazônicos - NAEA/ UFPA - entre 2004 e 2008. Foi Presidente da Associação Nacional de Pós-Graduação e Pesquisa em Planejamento Urbano e Regional ANPUR, gestão 2007-2009 e exerceu função de Diretora na Associação Nacional de Pós-Graduação em Sociologia - ANPOCS nos períodos (1986-1988 e 1994-1996), da Sociedade Brasileira de Sociologia - SBS (2009-2011). Atualmente é diretora da Sociedade Brasileira para o Progresso da Ciência - SBPC. Tem pesquisas e publicações nos temas: trabalho, políticas públicas, cidades, identidades e territorialidades de grupos tradicionais e conflitos sociais e ambientais, Amazônia, Pan-Amazônia, América Latina. 